\title{
METAPHORICAL CONCEPT - THE BEDROCK OF HUMAN BEING
}

\section{Olesya Cherkhava}

Doctor of Philology, Professor, Kyiv National Linguistic University, Ukraine e-mail: olesya_marchenko@yahoo.com,orcid.org/0000-0002-4504-0992

\section{Maria Homyak}

Master of Philology, Kyiv National Linguistic University, Ukraine e-mail: mashahomyak15@gmail.com,orcid.org/0000-0003-0952-7776

\section{Wladysław Majkowski}

Professor, Ph.D., Polonia University in Czestochowa, Interdisciplinary Faculty, Poland e-mail: wmajkowski@ap.edu.pl, orcid.org/0000-0002-3382-4511

\section{Summary}

This paper is an initial attempt to investigate the metaphorical concept from different linguistic perspectives. Concept acquisition in cognitive science ranges from metatheoretical to practical implications. The modern study of cognitive comparative linguistics is influenced by the development of new cognitive comparative discursive approach in the historical-comparative and typological language investigations. The traditional vision of the notion "concept" as the result of metaphorical process in human consciousness has challenged the cognitive diachronic concept acquisition. Cognitive paradigm in modern linguistics provoked new understanding of metaphor with broader conceptual view and complex methodology of its analysis. The research represents the cognitive processes of conceptualization and defines subsequences between the notions "conceptual metaphor", "metaphorical concept", "cognitive metaphor". The structure of the concept includes both everything that belongs to the concept, everything that makes it a fact of culture - the original form (etymology), history, modern associations and evaluation. These are the clots of the cultural environment reflected in the human mind.

Keywords: concept, metaphorical concept, concept structure, cognitive comparative linguistics, historical-comparative linguistics, typological linguistics.

DOI: https://doi.org/10.23856/4002

\section{Introduction}

The study of the metaphorical concept in modern linguistics is of the paramount importance. The comprehensive study of it in the field of cognitive comparative linguistics, the historical-comparative and typological investigations confirmed inequality in the definitions of its adjoining notions "cognitive metaphor", "conceptual metaphor". In order to avoid ambiguity and terminological confusion it is necessary to define these discrepancies. Cognitive metaphor possesses transformational character and the result of polysemy development that forms abstract meaning (Popova, 2007: 4). According to other scientists, its peculiarity is represented in attributing to the subject a metaphorical transfer of features, properties and actions characteristic of another class of objects. Conceptual metaphor is associated with a number of the most diverse points of view, one of them is that this term represents deep understanding of one phenomenon (picture of the world in the forms of frames and scenarios 
used to comprehend the abstract notions) in the terms of other (Lacoff, 204 :203). On the contrary, metaphorical concept is viewed as a special conceptual carrier of ethnocultural stereotypes - one of the most accurate forms of world perception that simplifies and accelerates information perceiving.

\section{Metaphorical concept in the scope of terminological controversy}

Yu. Stepanov represented the concept as a mental formation with the "layered" kernel-periphery structure: inner etymological criterion, urgent strata that identifies the ways of acquiring conceptual figurative/metaphorical meaning, everything that is added by culture, traditions and people's personal experiences. Despite the significant achievements of various aspects of the theory of metaphorical cocept it is represented by a small number of works.

The integration of linguistic, culturological, and psychological approaches to metaphoric model learning has contributed to the emergence of diverse points of view - metaphor as similarity transference is based on paradigmatic associations, as a universal way and means of human thinking, as a feature of the national language and folklore, as the mean of forming concepts that is consistent with the basic values of a particular culture, which reflects and preserves them. Metaphor has entered into the notional system of cognitive linguistics as the phenomenon that reflects certain laws of the human psyche, the peculiarities of worldview, as well as captures a number of cultural and historical facts of life of a society (people), should become the main object of linguistic and cultural research. The complex nature of metaphor, as the basic unit not only of language but also of the basic way of thinking, encourages to a number of related (integral) directions of its study, including linguocognitive, anthropocentric and philosophical thought.

The intensive research of metaphor in the field of cognitive linguistics has demonstrated a great disparity in the understanding of the term "metaphoric concept" - cognitive way of perceiving information. It is necessary to distinguish metaphorical concept and facilities of its realization in a language (metaphorical constructions and word-combinations).

The process of creating a metaphor is a complex phenomenon, the result of mental and linguistic activity of man, which is based on the cultural-historical, cognitive-empirical experience of peopleprovides it with great reconstructive opportunities in the study of the development of the linguistic picture of the world.

The metaphorical concept is also a unit of the collective consciousness, which is stored in the national memory of native speakers in verbally determinate form. As a mean of replenishing the vocabulary, metaphor forms and expands the lexical meaning of words, as well as the main way of cognitive and mental activity. It has the ability to act as a model (image-scheme) of human knowledge in consciousness and at the same time give them linguistic expression. At the same time, concept, as the cognitive unit of meaning that is associated with a corresponding representation in a language - is an abstract idea or a mental symbol sometimes defined as a "unit of knowledge", built from other units which act as a concept's characteristic. A cognitive approach to the metaphor in the scope of the linguistic conceptualization is crucial in the process of the English axiological and religious worldview. The relationship between the notions "metaphor" and "concept" has attracted the attention of many scholars for centuries. In contrast to the traditional approach, which considers metaphor only as a linguistic means and as a result of word substitution and contextual shifts, cognitive linguistics associates it with the mental processes accompanying the generation and perception of speech. According to the concept of American scientist s J. Lakoff and M. Johnson, who developed the theory of 
cognitive metaphor, "our everyday conceptual system, within which we think and act, is essentially metaphorical. Metaphors are already embedded in the very conceptual system of human thinking, nevertheless, we are not aware of the conceptual system" (Lakoff, 2001: 41). Thus, the metaphor is viewed as a tool that allows a person to cognize the surrounding reality, to structure his experience and knowledge. The actual understanding of the cognitive (conceptual) metaphor boils down to the fact that one object is seen through another due to the comparison of the unknown with the cognized in order to categorize objects of the surrounding world and represent the process of cognition in linguistic form. Consequently, metaphor is a mental operation that controls the process of cognition, categorization, conceptualization, evaluation and explanation of the world, as well as a tool for the interaction of culture, language and thinking. Throughout almost the entire tradition of its study, metaphor was considered purely as a means of emotional influence, which led to its study in rhetoric. The statement about this function of metaphor has become general, many authors have written about it. Not only a writer, publicist and public figure, but also any member of society is interested in the emotional pressure on the addressee. The common goal naturally gives rise to the commonality of the language techniques. The sphere of expression of emotions and emotional pressure introduces an element of artistry into everyday language, and with it a metaphor.

The modeling function of metaphor began to stand out in the XX century. J. Lakoff and M. Johnson put forward the thesis of the embedding of metaphor in thinking; metaphor was seen not only as a poetic and rhetorical means of expression, not only as belonging to natural language, but as an important means of presenting and understanding reality, as a means of forming a picture of the world. J. Lakoff and M. Johnson argue that metaphor permeates all everyday life and is manifested not only in language but also in thought and action. Our everyday conceptual system, within which we think and act, is metaphorical in its very essence (Lakoff, 2001: 44).

\section{The contemporary theory of metaphorical concept}

The concept is a scheme of structuring the field of knowledge, which lays the foundation for the development of further semantics. It lays down a system of representation of the relationship between its core (conceptual etymological component) and the periphery (value-image component), which reflects the ways the concept and its components-concepts acquire figurative / metaphorical meaning (according to Y. S. Stepanov and A. Korolyova).

Y. S. Stepanov believes that the structure of the concept includes both everything that belongs to the concept [...] and everything that makes it a fact of culture - the original form (etymology); [...] History; modern associations and evaluation [...] are clots of the cultural environment reflected in the human mind" (Stepanov, 2004: 55).

The meanings of words are correlated with certain cognitive contexts - cognitive structures, or blocks of knowledge that stand behind these meanings and provide their understanding. R. Goatly calls these cognitive contexts, or blocks of knowledge, "cognitive domains" (cognitive domains, spheres, or contexts).

Different people can associate the same concept with different ideas and images. These images act as "units of the subject code, they encode concepts in the human mind and provide the easiest access to their content". Concepts are "mental formations that are meaningful, recognizable, typified fragments of experience stored in a person's memory". The concepts bring together fundamentally important human knowledge of the world and exclude insignificant ideas. 
It should be noted that the concepts are the result of two tendencies: the desire to reflect the dialectic of the world, that is, to reflect the world as it is; and the desire to construct the world in order to subordinate it to the will and desire of a humanto present the world simpler, more rigid and deterministic to the extent that is necessary and sufficient for a human to solve practical problems.

In modern linguistics, conceptual metaphors are understood as stable correspondences between the source area and the goal area, fixed in the linguistic and cultural traditions of the ethnos, which form special cognitive structures containing information about certain areas of knowledge, and are stored in the memory of native speakers.

The study of metaphor as a mental phenomenon led to the consideration of the metaphorical concept (= conceptual metaphor) as a kind of abstract model ( $X$ is $Y$ ) which is realized as a result of its filling with new content. It is certain metaphorical expressions that reflect not only individual figurative representations of the world a separate native speaker of the language, but also typical collective representations specific to a particular linguistic culture (for example, a dispute is a war; time is money, etc.).

However, in some works, there is a confusion (up to complete identification) of the concepts of conceptual metaphor, metaphorical concept and metaphorical model, which makes the concept of a metaphorical concept amorphous and necessitates its further study.

The notion of a metaphorical concept, equivalent to the concept of conceptual metaphor, was introduced, as is known, by J. Lakoff and M. Johnson to describe the cognitive nature of metaphor (Lakoff, 2004, 45). At the turn of the XX - XXI centuries. The term "metaphorical concept" (= conceptual metaphor) is widely used in linguo-metaphorology, which was due to the formation of linguo-conceptology as an independent branch of linguistics and the emergence of various research methods of ethnocultural concepts. A metaphorical concept is usually interpreted as a stable correspondence between the source area and the goal area, fixed in the linguistic and cultural tradition of the ethnic group, or a special cognitive structure containing information about a specific area of knowledge and stored in the memory of native speakers. The experience of the case study of metaphorics on different materials and the description of metaphorical concepts / conceptual metaphors based on the author's methods is presented in the works of A. Baranov, Z. Rezanova, A. Chudinov. However, there is still no universally accepted definition of a metaphorical concept, its complex characteristics as a mental unit, and a unified analysis technique.

The metaphorical concept belongs to the field of consciousness. It has national and individual specifics, reflects the peculiarities of figuratively associative thinking of the ethnos and is objectified in metaphors (usual and occasional metaphorical meanings). It is characterized by a number of specific signs, the main of which are dominance, invariance, variability of linguistic (speech) representations and stability of associations.

A comparative study of different individual metaphorical conceptual spheres at a certain stage of historical development helps to identify common metaphorical concepts for a given ethnic group (in our case, literature of the period under study) and metaphorical concepts specific to its particular representative, reflecting, respectively, national stereotypes of figurative thinking and individual author's ideas about the world.

The description of the voluminous fragment of the metaphorical conceptosphere of the ethnos, reconstructed as a result of the reconstruction of several individual metaphorical conceptospheres on a significant body of texts, the identification of basic (high frequency of language and speech realizations) concepts and their comparative study, is based on the following principles: 
1) the core of the conceptosphere is formed by metaphorical concepts that are characteristic of all the studied individual conceptospheres;

2) group concepts that are inherent in the metaphor of two or more prose poets enter the nuclear zone;

3) individual concepts make up the periphery of the metaphorical conceptosphere. The establishment of basic metaphorical concepts that are characteristic of a number of authors as carriers of ethnoculture allows us to identify certain components of the general conceptual sphere of the ethnos at a certain stage of its evolution (Black, 2004: 25).

So, the concept and the metaphorical concept are two-sided unity: firstly, they unite homogeneous objects and their features, and secondly, they unite homogeneous linguistic expressions.

Understanding the nature of the concept of O. Kyslyanska (as an abstraction of homogeneous objects and their features) compares favorably with many modern theories of the concept in that it does not contradict the theory of cognitive metaphor by J. Lakoff and M. Johnson. In other words, based on the views of O. Kyslyanska, concepts are not interpretations of individual meanings of words, exclusively culturally specific entities or formations of the highest degree of abstraction.

On the one hand, there are representations and concepts, including metaphorical representations and concepts, and on the other, there are words, phrases, sentences and texts expressing these concepts and representations. It is obvious that new concepts are formed either from representations or from other concepts. Naturally, the very first non-metaphorical concepts were formed from representations.

Metaphorical cognitive structures are represented by metaphorical concepts, metaphorical representations and transition cases. Metaphorical concepts are the result of understanding the feature of one concept as a feature of another, metaphorical representations are the result of understanding the feature of one concept as a feature of another.

I. Sternin noted that a concept consists of components (conceptual features). It seems that the signs of a concept can be intra-conceptual and extra-conceptual. Intra-conceptual features include differential and non-differential features. Differential signs are the most general ones, they make it possible to distinguish one concept from another. These are signs of a concept at the concept level.

One concept passes into another, and as a result, the concept sphere of language is formed, and in the case of a literary text - the concept sphere of the text. The repetition and coherence of the components of metaphorical structures opens access to the conceptual information of the text, makes it possible to establish the features of metaphorical conceptualization in the mind of the author. The connectivity of metaphorical concepts and representations, in comparison with the connectivity of non-metaphorical concepts and representations, is more complex.

Intra-structural metaphorical connectivity is the relationship between non-metaphorical concepts and representations, the features of which are correlated within the framework of a cognitive metaphorical structure. Inter-structural metaphorical connectivity is the correlation of the components of different metaphorical concepts or representations.

Metaphorical connectivity is several times greater than the capabilities of non-metaphorical connectivity; it creates a whole network of interconnected components. If a concept is a set of common features of homogeneous objects, then a metaphorical concept is a set of correlated features of related concepts. If a representation is a collection of attributes of an object, then a metaphorical representation is a collection of correlated attributes of correlated representations. 


\section{Conclusions}

So, concepts are groups of words standing together as a conceptual unit, sayings, idiomatic expressions used in conversation in order to reflect in our minds information that is familiar for us (genetic code). In the controversy of terminological definitions, the traditional cognitive approach prefers conceptual metaphor as the conceptual mapping of one particular conceptual domain, whereas modern term metaphorical concept is used for mental unity that bears ethnocultural information about sereotype. It is a model of notions interaction on a similar basis that reflects the nature of metaphorical meaning due to the analogy between the conceptual areas.

\section{References}

Korolova, A. V. (2011). Diakhronichnyi vektor doslidzhennia struktur svidomosti y myslennia [Diachronic vector of the consciousness structure research]. Kyiv: Visnyk KNLU [in Ukrainian]. Kravtsova, Yu. V.(2011). Metaforycheskoe modelyrovanye myra: poezyia y proza [Metaphorical modelling of worldview: poetry and prose]. Kyiv: Vydavnyctvo NPU imeni M.P. Drahomanova [in Russian].

Karasyk, V. Y. (2001). Lynhvokulturny i kontsept kak edynytsa yssledovanyia [Linguistic cultural concept as the unity of investigation]. Voronezh: Vydavnyctvo Voronezh [in Russian].

Lakoff, Dzh. (2004). Metafory, kotorymi my zhyvem [Metaphors we live by]. M.: Prohress [in Russian].

Ohneva, E. A. (2013). Kohnytyvnoe modelyrovanye kontseptosfery khudozhestvennoho teksta [Cognitive modelling of conceptual sphere of literary texts]. M.: Edytus [in Russian].

Stefanova, N. O. (2018). Naukova argumentazia kriz pryzmu terminologichnyh analigiv [Scientific argument of the term "conceptosphere" through the scope of terminological analogues]. Herson: Herson Universyty Visnyk [in Ukrainian].

Stepanov, Yu. S. (2004). Konstanty: slovar russkoi kultury [Constants: the dictionary of Russian culture]. M.: Akademycheskyi proekt [in Russian]. 